\title{
Hypertrophic osteoarthropathy: four early reports by British authors (1889-97)
}

\section{DOYLE}

This paper draws attention to the substantial contribution made by British authors to the early reports on hypertrophic osteoarthropathy, or osteo-arthropathy as it was written in the period under review. A short account of the original papers by Marie and Bamberger is followed by discussion of four reports of special interest.

In 1886 Revue de Médecine published Pierre Marie's classic mémoire "Sur deux cas d'acromégalie." I In addition to his two cases, he included an abridged description of five other cases in the literature which he considered to be of the same nature as his own two cases (acromegaly). Four years later (1890) the same journal published another classic mémoire: "De l'ostéo-arthropathie hypertrophiante pneumique." 2 In his introduction he wrote: "Je désire d'abord débarrasser le champ de l'acromégalie de faits qui l'encombraient en pure perte puisqu'ils ne lui appartiennent pas, et qui risquaient ainsi de créer une confusion regrettable ...." Later he gave an account of one case of hypertrophic osteoarthropathy associated with chronic intrathoracic sepsis and, as previously, he added abridgments of four similar case histories, two from his 1886 article and two that had been reported separately in Britain. Clearly, by 1890 Marie had appreciated the cardinal points in the history and clinical findings whereby acromegaly and hypertrophic osteoarthropathy might be differentiated. Bamberger (1889) in a short report described bone changes associated with bronchiectasis ${ }^{3}$ and two years later (1891) reported in full a series of cases with similar changes. ${ }^{4}$

The first report of hypertrophic osteoarthropathy in Britain was by Saundby from the General Hospital, Birmingham. 5 The report, entitled "A case of acromegaly," was published in March 1889, after the publication of Marie's 1886 article, but before publication of the articles by Bamberger and the further articles by Marie. Saundby described a 38 year old

Address for reprint requests: Dr L Doyle, Wythenshawe Hospital, Manchester M23 9LT.

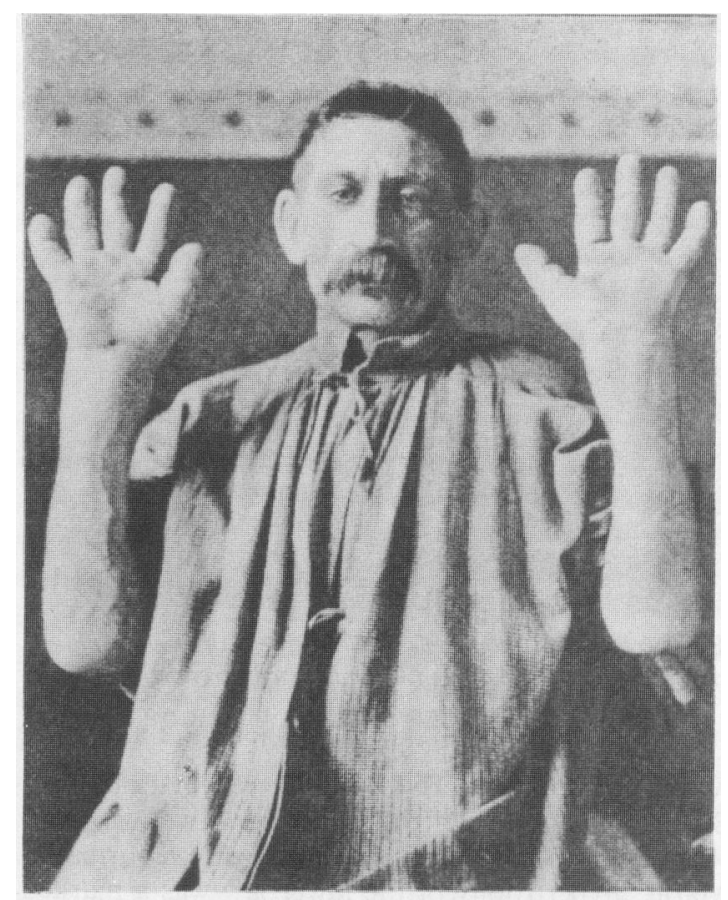

Fig 1 Bilateral symmetrical enlargement of hands and wrists. Reproduced from Saundby's case report of 1889.5

man with a short history of enlargement of both hands and feet; pain and stiffness in the ankles, knees, and wrists and clumsiness in his hands-."... and his feet grew so large that he could not get his boots on" (figs 1 and 2). He also complained of thirst. The patient died five months after the onset of symptoms. A postmortem examination was carried out, "at the patient's home and under difficult circumstances. A greyish round mass as large as an orange was found in the lower lobe of the left lung ... the growth was a spindle-celled sarcoma growing from the wall of a branch of the pulmonary artery ... the pituitary body 


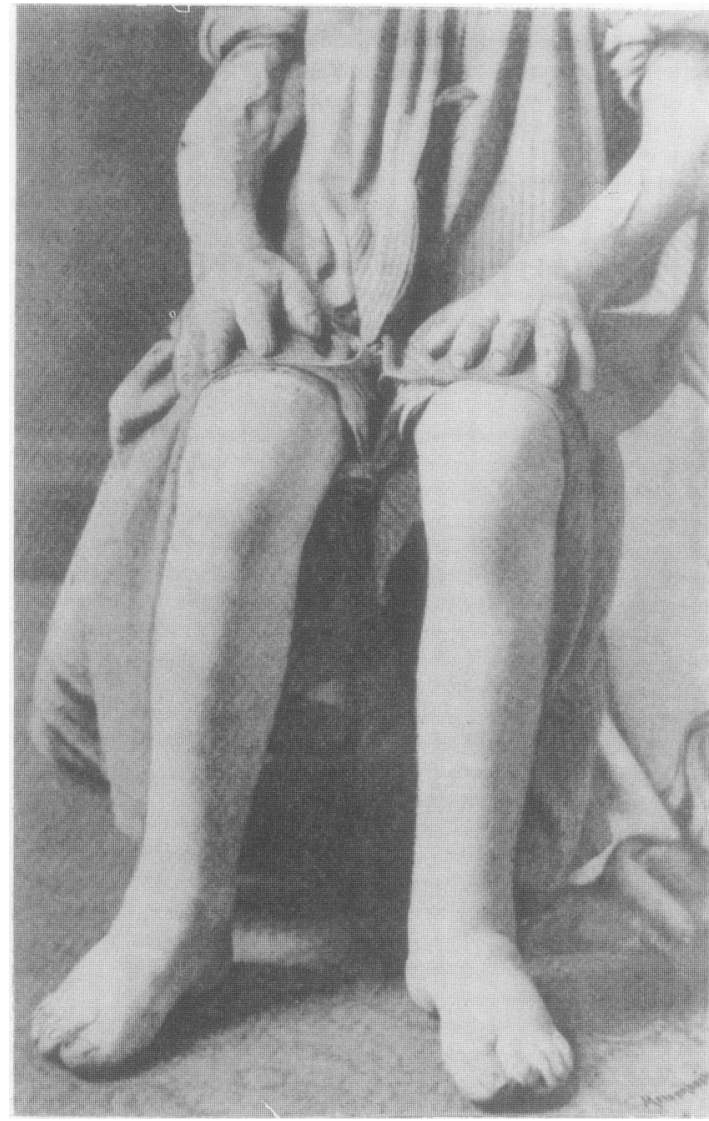

Fig 2 Bilateral symmetrical enlargement of knees, ankles, and feet. Reproduced from Saundby's case report of 1889.5

was quite normal." The bones were not examined. Saundby noted that the lower jaw was normal, whereas in the two cases of acromegaly reported by Marie "hypertrophy of the lower jaw was a marked and striking deformity." Marie incorporated details of Saundby's case in his 1890 account of the clinical features of hypertrophic osteoarthropathy.

In 1902 Saundby, now professor of medicine at the University of Birmingham, in demonstrating a case of hypertrophic osteoarthropathy secondary to bronchiectasis at the Birmingham and Midland Counties branch of the British Medical Association, referred to his 1889 case of hypertrophic osteoarthropathy associated with a malignant tumour of the lung. ${ }^{6}$ Saundby was clearly influenced by Marie's report of 1886 , as he entitled his case "A case of acromegaly." Marie in turn incorporated this case report in his 1890 mémoire. Saundby doubted that there had been a causal relationship between the bone and joint changes and the malignant tumour in the lung. None the less, he was the first to record their presence together in the $\overrightarrow{\vec{c}}$ same patient. Thorburn (later Sir William) in 1893 at $\overline{0}$ Manchester Royal Infirmary presented three cases ${ }^{7}$ 음 and was the first in Britain to use the title hyper- $\frac{\bar{c}}{1}$ trophic pulmonary osteoarthropathy. The first $\mathbb{\Phi}$ patient, a man of 21 , had a psoas and lumbar abscess and had been treated for spinal caries for ${ }^{\circ}$ five years. For the previous 18 months he had been $\vec{\circ}$ noted to have "marked enlargement of both hands $\overrightarrow{\vec{\omega}}$ and feet, perfectly symmetrical in character but $\stackrel{\sigma}{\omega}$ unaccompanied by any other indications of acro- $\vec{\sim}$ megaly.... The hands are enormous and at once attract attention; an estimate of their size was ${ }^{\mathrm{N}}$ obtained by measuring the displacement of a column on of water, produced by the immersion of the patient's $\stackrel{9}{\rightarrow}$ hand, and that of several healthy individuals of the 을 same age and sex, each being inserted to 2 inches above the styloid processes; the average displacement thus obtained from healthy hands was $12.5 \mathrm{oz}$, that of the patient's being $22.5 \mathrm{oz} \ldots$ the feet present $\stackrel{\text { क }}{\rightarrow}$ quite analogous appearances." The finger ends were $\vec{\oplus}$ bulbous. Physical signs in the chest suggested the presence of "phthisis with vomica in the left apex.". Initially, there may have been some doubt about the differential diagnosis as "the patient has been shown to the members of the Manchester Medical Society and to a large number of students, but no one has $\frac{\varnothing}{\varnothing}$ found his head or face remarkable."

The patient died in 1895 . The postmortem exam- $\overline{\bar{O}}$ ination, the fullest ever recorded in a case of hyper- 3 trophic osteoarthropathy up to that time, was published in Transactions of the Pathological Society of London. ${ }^{8}$ There were cicatrices (probably the sequelae of tuberculosis) in both upper lobes and evidence of $\frac{\text { 을 }}{2}$ previous tuberculous disease in several lower dorsal $\times$ and upper lumbar vertebrae. Both liver and spleen 3 showed noticeable changes of amyloid disease. Photographs included in the report showed "sub- $\frac{\circ}{3}$ periosteal sheaths" on a femur, tibia, fibula, radius, and ulna and on the metacarpal bones and the phalanges of one hand.

Thorburn (1893) initially suggested that hypertrophic osteoarthropathy "is in reality a tubercular $\odot$ affection of a large number of bones and joints, but $N$ that it is of a benign type having no tendency to break ్N down or caseate." In the postmortem report, how- $\sigma$ ever, he conjectured, "it is not inconceivable that the periostitis and amyloid lesions may be joint effects of a common cause or that the chemical disturbances $\stackrel{\oplus}{\rightarrow}$ resulting from amyloid disease may lead to the production of a poison capable, under certain circumstances, of causing periostitis. In our case the theory $\stackrel{\mathbb{D}}{\mathbb{D}}$ of absorption and toxic periostitis is met by the $\frac{}{\Phi}$ difficulty that we had no large decomposing accumu- 을 lation." The cause of the hypertrophic osteoarthropathy in this case was presumably post- 
tuberculous bronchiectasis. This case illustrates the persisting difficulty in making a clear clinical differentiation between acromegaly and hypertrophic osteoarthropathy and the early use of bone radiographs in the diagnosis of hypertrophic osteoarthropathy.

In 1896 Rickman Godlee, surgeon to the Brompton Hospital, delivered a paper at the hospital entitled "Clinical lecture on bone and joint changes in connection with thoracic disease," $90 \%$ of which was devoted to hypertrophic osteoarthropathy. In his introduction he recalled: "In my lecture on empyema, delivered at the Brompton Hospital in 1885, I mentioned amongst the sequelae of chronic empyema ... great clubbing of the fingers and in some cases similar swellings about the wrists, ankles, and the nose ... It is a poor satisfaction to be able to claim that one was the first to describe a particular disease, if it is necessary to add that the case was imperfectly observed and that its real nature was not recognised. I am afraid however that this is true." A cri de coeur! One case on which his 1885 observations on chronic empyema were based was described: "A youth, aged about 19 , had had for years a long piece of drainage tube in his pleura. I think it was 11 inches long and in for 9 years. It had slipped in soon after the opening of an empyema. He had marked clubbing of the fingers and toes and nose, and very obvious swelling of the wrists and ankles and, I think, knees; but I did not take careful notes of them. The tube was removed by Sir Joseph Lister. The empyema closed, and the clubbing and the swelling of the joints quite disappeared."

Godlee then described five further cases, of which three had hypertrophic osteoarthropathy and some form of chronic intrathoracic sepsis. One was of special interest: a man of 25 who three years previously had had left sided pleurisy. At the time of the examination, he wrote, "The left side of the chest is retracted and presents physical signs which may be interpreted as meaning either fibroid phthisis and bronchiectasis, or a localised empyema with bronchiectasis ... the expectoration amounts to a pint or more in $\mathbf{2 4}$ hours ... there is marked finger clubbing. The nails are reeded ..." Reeded nails (a good description) refer to the longitudinal striae of finger and toe nails noted with hypertrophic osteoarthropathy. There was swelling and impairment of movements in the wrists, knees and ankles. These changes had been present for three years, starting four months after the onset of pleurisy.

A few months later Godlee reported ${ }^{10}$ : "I saw him yesterday. $\mathrm{He}$ is no longer a sullen and morose individual, a typical example of a patient who is suffering from a prolonged suppuration, but a bright healthy man practically recovered from his ailment. He says that ten weeks ago there was a sudden increase of expectoration-about three-quarters of a pint of badly-tasting yellow stuff coming up between $10 \mathrm{am}$ and $6 \mathrm{pm}$ on one particular day. Next day he coughed once or twice and since then there has been no expectoration except when he has caught a cold, and then only a small amount of mucus. He had increased $21 \mathrm{lbs}$ in weight, his appetite and digestion are now good, and his bad temper has disappeared. But the main interest in the case is this-that the clubbing of the fingers has almost gone, and not only has he had no more pain in the joints but the swelling has disappeared, and they now present a normal appearance. All this had happened in ten weeks ..." This dramatic event was presumably the spontaneous and full expectoration of an empyema which had been encysted or draining poorly via a bronchopleural fistula. Thus Godlee missed the opportunity to be the first to describe hypertrophic osteoarthropathy, but he did record two cases of hypertrophic osteoarthropathy that resolved after the primary pleural or lung disorder had been rectified.

Steven (1897), in the Glasgow Medical Journal, reported a man aged 48 whose clinical history, findings, and pictures indicated the presence of considerable hypertrophic osteoarthropathy. ${ }^{11}$ Radiographs showed the presence of new periosteal bone on the shafts of finger bones, metacarpal bones, and the lower three-quarters of the shafts of a radius and an ulna. "The lungs, especially, are found to be quite healthy and he has had neither cough, spit, elevation of the temperature, or any indication whatever of lung disease during the two months he has been under observation. He suffers, however, from a chronic erythema of the face, with moderate desquamation, a condition which was present before his admission; and during residence he has also complained of flushings of the face ..." Did this patient have the carcinoid syndrome and a bronchial carcinoid tumour which, by virtue of its small size or position in the lung, escaped detection on physical examination?

These four articles, written 90-100 years ago, suggest that at that time chronic intrathoracic sepsis predominated over intrathoracic malignancy as the primary disorder associated with hypertrophic osteoarthropathy. They reported that relief of the primary disorder was followed by relief of symptoms of hypertrophic osteoarthropathy. We may reasonably speculate that if Godlee had recorded his 1885 lecture at the Brompton Hospital, London, and if Saundby had entitled his 1889 case report other than one of acromegaly, these two names might have had an eponymous association with the interesting condition of hypertrophic osteoarthropathy.

I wish to thank Mrs C Hukins, librarian of the Medical Postgraduate Centre, Wythenshawe Hospi- 
tal, for her help in the translation of the French articles, and Caroline McNally and Margaret Culliney for secretarial help.

\section{References}

1 Marie P. Sur deux cas d'acromégalie. Revue de Médecine 1886;6:297-333.

2 Marie P. De l'ostéo arthropathie hypertrophiante pneumique. Revue de Médecine 1890;10:1-36.

3 Bamberger E. Case reports. Wein Klin Wochenschr $1889 ; 2: 226$.

4 Bamberger E. Ueber Knochenveränderungen bei Chronischen Lungen und Herzkrankheiten. Zeitschr Klin Med 1891;18:193-217.
5 Saundby R. A case of acromegaly. Illustrated Medical $\overrightarrow{\vec{F}}$ News 1889;2:195-8.

6 Saundby R. Pulmonary osteo-arthropathy. Br Med J 1902;i: 1447.

7 Thorburn W. Three cases of "hypertrophic pulmonary osteo-arthropathy" with remarks. Br Med J 1893;i: ¿ $1155-9$.

8 Thorburn W, Westmacott FH. The pathology of hypertrophic osteo-arthropathy. Transactions of the Pathol-. ogical Society of London 1896;47:177-90.

9 Godlee RJ. Clinical lecture on bone and joint changes in $\omega^{\omega}$ connection with thoracic disease. Br Med J 1896;ii: 57-8, 116-9.

10 Godlee RJ. Pulmonary osteoarthropathy. Br Med $J \stackrel{\mathrm{N}}{\mathrm{D}}$ 1896;ii:1417-8.

11 Steven JL. A case of the so-called hypertrophic pulmon- 음 ary osteo-arthropathy of Marie, without pulmonary disease. Glasgow Medical Journal 1897;48:241-52. 